\title{
The creation of institutional reality, special theory of relativity, and mere Cambridge change
}

\author{
Tobias Hansson Wahlberg ${ }^{1}$ (D)
}

Received: 6 January 2019 / Accepted: 11 October 2019 / Published online: 25 October 2019

(c) The Author(s) 2019

\begin{abstract}
Saying so can make it so, J. L. Austin taught us long ago. Famously, John Searle has developed this Austinian insight in an account of the construction of institutional reality. Searle maintains that so-called Status Function Declarations, allegedly having a "double direction of fit" (i.e. a world-to-word and a word-to-world direction of fit), synchronically create worldly institutional facts, corresponding to the propositional content of the declarations. I argue that Searle's account of the making of institutional reality is in tension with the special theory of relativity-irrespective of whether the account is interpreted as involving causal generation or non-causal grounding of worldly institutional facts - and should be replaced by a more modest theory which interprets the results of Status Function Declarations in terms of mere Cambridge change and institutional truth. I end the paper by indicating the import of this more modest theory for theorizing about the causal potency of institutional phenomena generated by declarations.
\end{abstract}

Keywords Cambridge change - Causation · Declarations · Grounding - Institutional facts $\cdot$ Searle $\cdot$ Social ontology $\cdot$ Special theory of relativity $\cdot$ Speech acts

\section{Introduction}

John Searle famously maintains that all of institutional reality is created by "Status Function Declarations" (Searle 2010: pp. 13, 93, 99). Status Function Declarations fall into the category "extralinguistic declarations", a category of speech acts that Searle distinguishes from mere "linguistic declarations" (Searle 1989: pp. 549, 554-555, 2010: pp. 110-114). Linguistic declarations create speech acts (such as promises, statements and orders), but extralinguistic declarations create extralinguistic facts and entities in the world. Extralinguistic declarations are, conceptually,

Tobias Hansson Wahlberg

tobias.hansson_wahlberg@fil.lu.se

1 Department of Philosophy, Lund University, LUX, Helgonavägen 3, Box 192 (Billing address Box 188), 22100 Lund, Sweden 
of two kinds: supernatural declarations and Status Function Declarations (Searle 1975/1979: pp. 18, 1989: pp. 549-550, 2010: p. 100). Although we cannot, as human beings, successfully perform supernatural declarations, we can, according to Searle, change the world and create institutional facts and objects through Status Function Declarations.

In Searle's own words:

Naively the best way to think of the distinction [between linguistic and extralinguistic declarations] is this: A declaration is a speech act whose point is to create a new fact corresponding to the propositional content. Sometimes those new facts are themselves speech acts such as promises, statements, orders, etc. These I am calling linguistic declarations. Sometimes the new facts are not further speech acts, but wars, marriages, adjournments, light, property transfers, etc. These I am calling extralinguistic declarations. [...] When God says, "Let there be light!", that I take it is a declaration. [...] It makes it the case by fiat that light exists. [...] We ordinary humans do not have the ability to perform supernatural declarations, but we do have a quasi-magical power nonetheless of bringing about changes in the world through our utterances. (Searle 1989: p. 549) We can create boundaries, kings, and corporations by saying something equivalent to "Let this be a boundary!" "Let the oldest son be the king!" "Let there be a corporation!" [...] in the nonlinguistic Status Function Declaration, we do more than represent: we create. (Searle 2010: pp. 100, 114)

Moreover, according to Searle, Status Function Declarations generate their worldly changes synchronically - that is, simultaneously with the performance or application of the relevant Status Function Declaration (Searle 1989: pp. 556-557, 2010: p. 99). This should be contrasted with how directives and commissives, such as orders and promises, generate their worldly changes: such speech acts, if successful, have their characteristic worldly effects at later points in time (e.g. Searle 1975/1979: pp. 14, 19).

Searle is sometimes criticized on grounds that it is doubtful that all of institutional reality is created through declarations: much of institutional reality seems rather to evolve gradually and unintentionally, without the performance and acceptance of declarations (see e.g. Blackburn 2010; Epstein 2014; Lawson 2016). In this paper, I ignore this kind of criticism and focus instead on the kinds of example where Status Function Declarations intuitively do play an essential role. ${ }^{1}$ I argue that it is deeply problematic to speak of Status Function Declarations, such as verdicts, appointments, gradings, and incorporations, as literally "changing the world" - that is, as creating worldly "extralinguistic facts" (typically of the form, a's having institutional property or status function $Y$ ) that "correspond" to the propositional content of the declarations, as claimed by Searle. The Searlean view is intuitively problematic already within a commonsensical Newtonian framework-what could the relevant mechanism be (cf. Effingham 2010: p. 253)?-but it is decisively troublesome

\footnotetext{
1 Searle himself seeks to dispel such worries by defining "institutional" in terms of imposed status functions and by allowing implicit declarations (2010: pp. 13, 21-23, 2014).
} 
within a relativistic setting. Famously, instantaneous causation between spatially separated events is precluded in relativistic (Minkowskian) spacetime, meaning that a causal interpretation of Status Function Declarations (see e.g. Searle 1983: pp. 171-173) is ruled out; and synchronic grounding of an institutional fact by a Status Function Declaration (cf. Searle 1989, 2010: p. 4; Schaffer forthcoming) will, in a suitable reference frame in relativistic spacetime, involve backward grounding of the institutional fact, meaning that a grounding account of Status Function Declarations is in trouble too. To avoid such problems, it is preferable, I shall argue, to characterize the "results" of Status Function Declarations in terms of so-called mere Cambridge changes and institutional truths. This more modest conceptualization avoids giving a false picture of what happens when we perform Status Function Declarations and allows for simultaneous "generation" of institutional phenomena across reference frames, even within a relativistic framework. The conceptualization also has ramifications for the way we theorize the causal standing of the putative institutional phenomena.

The structure of the paper is as follows: I begin by describing Searle's theories of declarations and Status Function Declarations (Sect. 2). (Readers well acquainted with these theories may skip to Sect. 3.) I then criticize Searle's theory of Status Function Declarations-first, when construed as involving causation, subsequently, when interpreted in terms of grounding-drawing on the special theory of relativity (STR), (Sect. 3). Following this, I develop an alternative account in which the notions of mere Cambridge change and institutional truth play a key role (Sect. 4). I conclude with some observations about the implications of the alternative account (Sect. 5).

\section{Declarations and status function declarations}

Searle originally stated his general theory of declarations in his (1975/1979), where a taxonomy of illocutionary acts is developed. ${ }^{2}$ He explains:

It is the defining characteristic of this class [of illocutionary acts] that the successful performance of one of its members brings about the correspondence between the propositional content and reality, successful performance guarantees that the propositional content corresponds to the world. [...] Declarations bring about some alteration in the status or condition of the referred to object or objects solely in virtue of the fact that the declaration has been successfully performed. (Searle 1975/1979: pp. 16-17)

He symbolizes the structure of declarations thus (ibid.: 19):

$$
D \uparrow \downarrow \varnothing(p)
$$

\footnotetext{
${ }^{2}$ The taxonomy takes its cues from Austin's pioneering How to Do Things with Words (1962) and Searle's Speech Acts (1969).
} 
" $D$ " stands for declarational illocutionary force or point; the arrows indicate that declarations have both words-to-world and world-to-words direction of fit (as explained below); the null symbol indicates that there is no sincerity condition (this seems intuitively wrong, but for our purposes, this aspect can be ignored ${ }^{3}$ ); and " $p$ " stands for the propositional content of the declaration.

Searle explains what is involved in the idea that declarations have a "double direction of fit" by contrasting declarations with other types of illocutionary act. Thus, in Making the Social World (2010) he writes:

Some speech acts [e.g. statements] function by purporting to represent how things are in the world. [...] I think of these speech acts as hovering over the world and pointing down to it, as fitting or as failing to fit the world, as having what I call the word-to-world direction of fit. I represent these with the downwards arrow $\downarrow$. [...]

But there are lots of speech acts that are not in the business of trying to tell us how things are in the world. They are trying to change the world to match the content of the speech act. [...] The order is aimed at causing obedience; the promise is aimed at causing fulfillment. [...] I say of these cases that they have the world-to-word direction of fit. [...] I represent the upward or worldto-word direction of fit with an upward arrow $\uparrow$. [...]

There is a fascinating class of speech acts that combine the word-to-world $\downarrow$ and the world-to-word $\uparrow$ direction of fit, which have both directions of fit simultaneously in a single speech act $\uparrow \downarrow$. These are cases where we change reality to match the propositional content of the speech act and thus achieve world-to-word direction of fit. But, and this is the amazing part, we succeed in doing so because we represent the reality as being so changed. More than three decades ago, I baptized these as "Declarations." They change the world by declaring that a state of affairs exists and thus bringing that state of affairs into existence. (Searle 2010: pp. 11-12)

As we saw in Sect. 1, some declarations bring speech acts of other kinds into existence. ${ }^{4}$ Others bring extralinguistic phenomena into existence: these phenomena might (at least logically) be physical (created by "supernatural declarations") or institutional (created by "Status Function Declarations"). In the rest of the paper, I focus on Status Function Declarations.

\footnotetext{
${ }^{3}$ Searle seems to have retracted this view about the sincerity condition in later work (e.g. Searle 1983: p. 172, 1989).

${ }^{4}$ E.g., if someone says "I order you to leave the room", that person is, according to Searle, making a declaration with the following illocutionary structure: "Declare [that I order (that you leave the room)]" (Searle 1989: p. 541). Thus, the declaration brings an order into existence. Moreover, the order is a "performative", although the declaration is not (ibid.): the person explicitly utters "I order ...", but does not explicitly say "I declare...". Thus, declarations can be implicit or non-performative in the sense that they need not token an explicit expression naming the illocutionary force of the speech act (this is true of other speech acts as well). Indeed, according to Searle, to perform a declaration we need not even explicitly utter (or, I take it, write) anything: "I need not say anything. Just pushing the beer in the direction of their new owners can be a [declarational] speech act" (Searle 2010: p. 89).
} 
In his (2010: p. 93), Searle maintains that the "general form" of Status Function Declarations is:

We (or I) make it the case by Declaration that the Y status function exists.

A status function is a function (i.e. "a cause that serves a purpose", Searle 2006: p. 17, 2010: p. 59) with two special but interrelated features:

First, $[\ldots]$ they require collective intentionality, both for their initial creation and for their continued existence. And second, they are functions that a person or other entity has, not in virtue of physical structure, $[\ldots]$ but in virtue of collective imposition and recognition of a status. (Searle 2010: p. 59, see also 1995: pp. 40-51, 2010: pp. 7, 102-104)

Status functions, then, are additional to the physical powers or abilities of objects, and imposed on objects through Status Function Declarations. Their continued existence requires their ongoing acceptance or recognition by a plurality of individuals in the society in question (Searle does not specify how large the fraction of accepting individuals needs to be).

By declaring a status function into existence, we create an institutional fact or state of affairs (e.g. Searle 2010: p. 93). Crucially, for Searle, a fact or state of affairs is not merely a true proposition or statement (Searle 1995: pp. 205-206, 220). He rejects such a Fregean view of facts on the ground that "facts function causally in a way that true statements do not" (1995: p. 205). Facts are rather worldly things to which true statements correspond (Searle 1995: p. 202); they are entities that make statements true:

... the fact stated needs to be distinguished from the statement of it [...] the whole point of having the notion of "fact" is to have a notion for that which stands outside the statement but which makes it true, or in virtue of which it is true, if it is true. (Searle 1995: pp. 2, 211, emphasis in original; see also Austin 1950/1979: pp. 121-124)

In some places Searle is content to describe such facts loosely as "conditions in the world" (Searle 1995: p. 211). In other places, he seems to accept a more specific and traditional understanding of facts or states of affairs (cf. e.g. Armstrong 1997): facts are "entities in the world that have a propositional structure" (e.g. Searle 2014: p. 19); that is, a fact is (I read Searle as saying) a structured entity consisting of an object with a certain feature or property (or a constellation of objects standing in certain relations to each other). On yet other occasions, Searle uses the term "fact" to denote various things, such as events, actions, speech acts, properties, and objects (e.g. Searle 1989: passim, 2010: passim, 2010: passim). Although these conceptions of factuality differ, it is clear that Searle wants to use "fact" to pick out a worldlyand potentially causal-entity (or condition or structured complex), as opposed to an abstract linguistic entity, such as a true proposition. 
Importantly, institutional facts are to be contrasted with brute facts (Searle 1995: pp. 2, 27). Brute facts, such as Earth's being 93 million miles from the sun, exist independently of any human institution. ${ }^{5}$ Institutional facts, such as Donald Trump's being president of the U.S., require institutions for their existence-where institutions are systems of "constitutive rules" (1969: p. 51, 1995: p. 28), or as Searle prefers to put it in his (2010: pp. 10, 13): systems of Status Function Declarations. ${ }^{6}$ The essential point is that, "all institutional facts are created by the same logical operation: the creation of reality by representing it as existing" (Searle 2010: p. 93).

The overall idea concerning institutional reality, then, is that statements about institutional reality are made true by institutional facts (Searle 1995: p. 221); and institutional facts are brought into existence by Status Function Declarations (Searle 2010: p. 13). ${ }^{7}$

Before I move on I should point out the following. For Searle, there is a strong connection between status functions and so-called deontic powers, i.e., rights, duties, permissions, obligations, etc. (1995: pp. 100-101, 2010: pp. 8-9). Searle sometimes puts this by saying that "status functions carry deontic powers" (2010: p. 8). For example, a person who acquires the status function of being president of the Unites States thereby acquires certain rights and duties. But though there is a strong connection between status functions and deontic powers, they should not, I think, be identified on Searle's scheme of things. For example, the status function of being money may be imposed on certain pieces of paper, but the associated right to use those pieces of paper as payment belongs to the owner of the money, not the paper items (1995: pp. 95-96, 101, 2010: pp. 101-102). Thus, status functions do not reduce to deontic powers, since status functions and their associated deontic powers may very well be had by distinct entities.

It is also worth stressing that, for Searle, institutional facts, status functions and institutional objects do not exist in people's minds (pace e.g. Johansson 2003: p. 247). Institutional phenomena somehow depend on mental phenomena of the kind

\footnotetext{
5 Searle is influenced here by Anscombe (1958).

6 "Constitutive rules" paradigmatically take the form "X counts as Y in context C"; they should be contrasted with merely "regulative rules", typically of the form "If Y do X" (Searle 1969: pp. 33-36, 1995: pp. 27-28; for critical discussion of the contrast, see Hindriks 2009). In his 2010-book, Searle analyses constitutive rules as cases of "standing declarations" with double direction of fit (2010: pp. 13, 97). It transpires, then, that for Searle, declarations can be understood either as speech acts (events or actions), which are performed by individuals, or as rules (a kind of object), which are represented (accepted or recognized) by individuals. Thus, there is a kind of process/product-ambiguity in Searle's notion of declaration.

7 The "general form" of Status Function Declarations (see above) can, according to Searle, be implemented in various ways (2010: pp. 99-100): we can impose status functions on pre-existing objects (these are the paradigmatic cases) - either on an ad hoc basis, whereby constitutive rules about singular objects are in effect invented, or more systematically by involving general constitutive rules-and we can even create new objects like corporations "out of thin air" that have status functions (i.e., cases of socalled "freestanding Y terms", 2006: pp. 22, 2010: pp. 97-99). The various implementations will characteristically be of the following more specific forms: "We make it the case by Declaration that object $\mathrm{X}$ now has the status function $\mathrm{Y}$ in $\mathrm{C}[\ldots]$. We make it the case by Declaration that for any $\mathrm{x}$ that satisfies condition $\mathrm{p}, \mathrm{x}$ has the status $\mathrm{Y}$ and performs the function $\mathrm{F}$ in $\mathrm{C}[\ldots]$. We make it the case by Declaration that an entity Y exists that has status function(s) F in C." (Searle 2010: pp. 99-100).
} 
involved in collective acceptance, or recognition, of Status Function Declarations, but they are not identical with those phenomena. As Searle puts it: "we need to introduce a class of phenomena [money, property, government, etc.] that are not actually located in our minds but are dependent on our attitudes." (2010: p. 17, my emphasis) (Admittedly, there is a puzzling anti-realist strand in Searle's writing about institutional reality which is somewhat hard to square with the views and formulations summarized and quoted above. For example, at various places he says that institutional facts are "ontologically subjective" (e.g. 2010: p. 18). I will return to this seemingly irrealist aspect of Searle's theory at the end of Sect. 4.)

Finally, it should be noted that spelled-out declarations are typically presenttensed, and often they contain indexicals like "now". ${ }^{8}$ According to Searle, the present tense-or what he sometimes calls the "dramatic present" or the "present present" (1989: 556)—indicates that the creation of the represented fact, i.e. the event of creation, is simultaneous with the speech act:

This tense is used to mark events which are, so to speak, to be construed as instantaneous with the utterance. [...] In these cases, the sentence describes an event that is simultaneous with its utterance [...] Now, because the performative utterance is both self-referential and executive, the present present is ideally suited to it. "I promise to come and see you" [or "We make it the case by Declaration that object $\mathrm{X}$ now has the status function $\mathrm{Y}$ in $\mathrm{C}$ '] marks an event [the making of a promise, the creation of an institutional fact] which is right then and there, simultaneous with the utterance, because the event is achieved by way of making the utterance. (Searle 1989: pp. 556-557, my emphasis)

This synchronicity thesis is arguably entailed by the "double direction of fit" idea. If the worldly institutional fact were created at some point after the completion of the declaration, we would apparently have a case of world-to-word direction of fit, $\uparrow$; but according to Searle, in cases of declarations, we have $\uparrow \downarrow$.

I will turn now to examine the consequences of taking seriously the idea that we can synchronically create extralinguistic, institutional facts through Status Function Declarations, and thereby literally change the world. ${ }^{9}$

\section{Bringing reality into correspondence with propositional content through status function declarations? The lessons from STR}

Obviously, if someone utters something, the world thereby changes in the trivial sense that the very act of uttering is a process consisting of physical changes (the lips move, and so on). Clearly, however, this is not the kind of change Searle is talking about

\footnotetext{
${ }^{8}$ This is illustrated, e.g., by the explicit forms of the various Status Function Declarations discussed by Searle; see note 7 above.

9 Although I am primarily addressing Searle's theory, I think the problems I point out generalize: arguably they afflict any theory of institutional reality involving synchronic generation of institutional properties/objects/facts, understood as real entities, across spatially extended regions. Some problematic cases in point will be mentioned along the way (e.g. Elder-Vass 2012; Hindriks 2013; Schaffer forthcoming); but see also e.g. Thomasson (2003), Baker (2007: pp. 11-13), Hindriks (2009), and Smith (2014).
} 
when he says that we can change the world by making Status Function Declarations. There is nothing "amazing" (2010: p. 12), "quasi-magical" (1989: p. 549) or "godlike" (1983: p. 176) about such changes. Instead the idea is, as we have seen, that the world changes because an institutional fact (which, remember, is non-identical with a true proposition and with people's mental states) begins to exist in the world when a Status Function Declaration is made - a fact which corresponds to the propositional content of the speech act and which serves as a truth-maker of the declaration, yielding the success both of the declaration's world-to-word $\uparrow$ direction of fit and its wordto-world $\downarrow$ direction of fit. ${ }^{10}$ Thus, Searle appears to be asserting that beyond the physical and mental changes involved in lip movements and shared recognition, something more is created. It is the creation of this additional feature or thing-specifically, a "status function", such as being money, or an "institutional object", such as a corporation-which constitutes the relevant change or event in the world, and which allows us to refer, quite literally, to the creation of an institutional fact.

Let us take Searle at his word, and ask: Can the claim that institutional facts are created, or brought into existence, in the way he describes be reconciled with our best scientific theories of how the macroscopic world works ${ }^{11}$ - in particular, is it compatible with the tenets of the special theory of relativity (STR)? I shall argue that if the relevant change or creation is not local, i.e. does not have the same spacetime location as the declaration itself, the answer is No. ${ }^{12}$

Consider the marking of exam papers. When an authorized examiner assigns a grade to a student's script (and thereby to the student), in accordance with the marking scheme, say by signing a certain physical document or by entering information into a computer system, that act can be interpreted as an extra-linguistic declaration of the following form:

I declare: $\mathrm{NN}$ is hereby assigned grade $\mathrm{Y}$ in subject $\mathrm{S}$.

The examiner's declaration certainly makes it true that the student has acquired the relevant grade in the relevant subject. And Searle would in all likelihood regard the grading as an imposition of a "status function", since the grade (we may suppose) gives the student new deontic powers, such as being entitled to enroll on an

\footnotetext{
10 Thus, for Searle, successful declarations and performatives have truth values, pace the view of performatives originally developed by Austin (Searle 1989: pp. 540, 553; cf. Austin 1956/1979; 1962: p. 5, passim). Talk of features, objects or facts being "created" is also absent from Austin's writings. In general, Austin focuses on performative or illocutionary acts, not on the ontology of the results of such acts.

11 Compare Searle's own remarks: "The limitation on performatives [and declarations] is provided by the fact that only a tiny number of changes can be brought about in the world solely by saying that one is making those changes by that very utterance. For nonsupernaturally endowed human beings, these fall into two classes: the creation of purely linguistic institutional facts [...] and extralinguistic institutional facts $[\ldots][$ A]ny verb at all which names an intentional action could be uttered performatively. The limitations on the class that determine which will succeed and which will fail derive from facts about how the world works" (Searle 1989: pp. 554-555, 557, my emphasis).

12 Why has not anyone addressed this issue before (although see my 2014a and forthcoming for some brief remarks)? I guess most social ontologists are simply not very interested in STR and have therefore neglected the issue. And some might think that considerations from STR-a theory from natural science-are irrelevant to social ontology. I maintain that they are highly relevant.
} 
advanced course in the same subject (cf. Searle's discussions of convicted criminals, 1975/1979: p. 20, 1995: p. 50). ${ }^{13}$

Suppose now that the acquisition of the grade involves a genuine change in the world (beyond the agreed physical and mental changes): an instance of an institutional feature or property, grade $Y$ (a "status function"), is created. It is instantiated by the relevant student, $a$, and in this way a worldly institutional fact—a's having grade $Y$ —corresponding to the propositional content of the declaration is created. On this construal, it is natural to suppose that the change involving $a$ is an effect of the declaration, and that the grading and acquisition of the grade are a cause-and-effect pair (I will later discuss the possibility that they are related by an ontological dependence or grounding relation). Indeed, in his (1983) Searle explicitly defends a causal interpretation of declarations:

... what is [a person] trying to do when he makes a declaration? He is trying to cause something to be the case by representing it as being the case. More precisely, he is trying to cause a change in the world [...] in the case of directives, commissives, and declarations, the utterance, if satisfied, will in various ways function causally in the production of the state of affairs it represents. (Searle 1983: pp. 172-173, emphasis in original) ${ }^{14}$

However, since the acquisition of the grade occurs simultaneously with the grading, or its official completion, the relevant relata must be related by simultaneous causation if they are causally related. ${ }^{15}$ Worse, since the student and the act of grading are likely to be located in different places, the relevant causation will involve events that are both simultaneous and separated in space. ${ }^{16}$ But that is ruled out by STR: it says that no causal process can propagate outside the future light cone of an originating event - that is, no causal process can propagate faster than the speed of light, which is a constant and finite magnitude (299 $792458 \mathrm{~m} / \mathrm{s}$ ) across all reference frames (e.g. Taylor and Wheeler 1992: pp. 171, 181-182). ${ }^{17}$ Thus, if Status Function Declarations are supposed to bring about their simultaneous worldly changes by causal processes, the theory is straightforwardly at odds with STR (assuming non-locality). ${ }^{18}$

\footnotetext{
${ }^{13}$ Prima facie, the having of the grade might even involve causal potency: the grade might cause the student to lead a good—or if the grade is fail, a miserable—life. See Sect. 5 for an assessment of this idea.

${ }^{14}$ See also sociologist Dave Elder-Vass (2012: pp. 62-64) who, quite approvingly, interprets Searle's theory in causal terms.

15 In Sect. 4, I discuss cases that prima facie involve backward assignment of grade, from the point of view of the grader.

${ }^{16}$ The student may even have travelled to the other side of the Earth—or to the Moon, or whatnot, if a futuristic sci-fi scenario is entertained-when the official grading occurs. Thus, the distance between the grading and the putative acquisition of the grade might, in principle, be quite significant.

${ }^{17}$ For philosophical discussions of this speed-limit for causal propagation, see e.g. Reichenbach (1958), Salmon (1984), Mellor (1995), and Dowe (2000). See also my (2017) for critical discussion of Mumford and Anjum's recent endorsement of simultaneous power-causation (Mumford and Anjum 2011).

${ }^{18}$ This objection presupposes that causation is understood in terms of a continuous process connecting distinct events or worldly facts, which may seem obviously absurd in a case like the above. What if causation is taken instead to consist in mere counterfactual dependence between distinct events (e.g. Lewis 1973 - a view not endorsed by Searle, who characterizes causation in traditional non-Humean "efficient causation" terms, see e.g. Searle 1983: p. 135, 2001: p. 41)? Prima facie, counterfactual dependence obtains in the example in question, i.e. between the examiner's grading and the student's acquisition of
} 
A causal interpretation of synchronic declarational creation of institutional facts thus seems doomed. And, in his (1989), Searle appears to have changed his mind about the generative means, although he does not explain why. He now says:

In order intentionally to produce changes in the world through our actions, normally our bodily movements have to set off a chain of ordinary physical causation. [...] But there is an important class of actions where intention, bodily movement and desired effect are not related by physical causation in this way. If somebody says, "The meeting is adjourned," "I pronounce you husband and wife," "War is declared," or "You're fired," he may succeed in changing the world in the ways specified in these utterances just by performing the relevant speech acts. [...] the difference between pounding a nail and adjourning a meeting is that in the case of adjourning the meeting the intention to perform the action, as manifested in the appropriate bodily movement (in this case the appropriate utterance) performed by a person duly authorized, and recognized by the audience, is constitutive of bringing about the desired change. (Searle 1989: pp. 547-548, my emphasis)

Searle here seems to be suggesting that declarations - or the intentions behind them, and the collective recognition of them ${ }^{19}$ - and their associated changes are related, not by causation, but by a relation of constitution. However, since he also denies, as we saw in Sect. 2, that institutional phenomena are located in people's minds (2010: p. 17), this "constitution relation" cannot be conceived of in terms of identity. Rather, it seems that Searle is here alluding to a non-causal, asymmetric ontological dependence relation-in contemporary terms, to a grounding relation (see e.g. Schaffer 2009, forthcoming)_obtaining between non-identical phenomena ( $x$ grounds $y$ is simply the converse of $y$ depends ontologically on $x) .{ }^{20} \mathrm{An}$ account in terms of grounding is, at least prima facie, more appropriate, since, in contrast to causation, grounding is standardly taken to be a paradigmatically synchronic relation (see e.g. Bernstein 2016).

Footnote 18 (continued)

the grade. However, if the counterfactual dependence at issue concerns spatially separated but simultaneous events, Lewis tended to treat the dependence as non-causal: his diagnosis was that one of the events is, in all likelihood, "predominantly extrinsic" (here, presumably, $a$ 's acquisition of grade Y). According to Lewis, causation relates distinct events which are "predominantly intrinsic" (Lewis 1986b: pp. 263-264). My own diagnosis of the putative counterfactual dependence between declarations and their results (to anticipate what is to come in Sect. 4) is that the results (such as $a$ 's acquisition of grade Y) are in fact mere Cambridge changes; they do not even involve extrinsic properties, if extrinsic properties are understood as monadic (but relation-dependent) ontological correlates to monadic predicates (cf. Armstrong 1997: pp. 91-93).

19 Searle elsewhere clarifies that the collective recognition need not always be recognition of a specific event (e.g. of a specific declaration occurring at a certain place at a certain time) or of a particular object's status function; it may suffice that the collective recognition concerns general constitutive rules - "standing declarations" with general content (2010: p. 97) — which back up various singular declarations or the having of a status-function by a certain object (see e.g. Searle 2010: pp. 102-103, see also 1995: pp. 32-33, and 1975/1979: pp. 19-20).

20 Indeed, in his (2010: p. 4), Searle says that "social institutions such as governments and corporations are dependent on and derived from the mental phenomena and behavior of individual human beings." (my emphasis). 
Our question, then, is whether an account of Searlean declarational generation of institutional facts framed in terms of asymmetric ontological dependence or grounding is compatible with STR. I shall argue that the answer to this question is in the negative.

Apart from the fact that it is unclear what the mechanisms, if any, of grounding are supposed to be, a grounding account ${ }^{21}$ of declarational generation of institutional facts still faces the issue of simultaneity and spatial separateness: the relevant Status Function Declaration and the change in the world (the event of creation) are supposed to be simultaneous, and if the entity which acquires the status function is located at some place differing from the place of the Status Function Declaration, then, trivially, the declaration and the change are spatially separated. Thus, this kind of case is in an important respect different from the paradigmatic examples of grounding discussed in the grounding literature-wholes grounded in their parts, mental states grounded in brain states, tropes grounded in substances, sets grounded in their members-where the grounded phenomena are, typically, taken to be co-located with their grounds. Now, according to STR, it is a relative matter whether or not events which are spatially separated and exist in each other's "absolute elsewhere"-i.e. outside the lightcone of the other event in question-are simultaneous: events that are simultaneous in one reference frame are not simultaneous in another frame if the latter is moving at high speed relative to the former (e.g. Taylor and Wheeler 1992: pp. 62-63, 181). This is a problem for a grounding account of Searlean generation of worldly institutional facts by Status Function Declarations, because unless the account treats the relevant grounding as something that is in some reference frames directed backward in time-which is highly counterintuitive and violates Searle's simultaneity requirement ${ }^{22}$ - it will have to insist that the relevant events are simultaneous in all reference frames, in violation of STR.

Consider Fig. 1. In it, a student, $a$, and an examiner, $b$, who are spatially separated but (approximately) stationary relative to each other, are depicted. During the time interval shown they agree on the simultaneity of events: they slice up spacetime into the same set of simultaneity planes (or times or hyperplanes of spacetime). The grading, $e$, and the acquisition of the grade, $e^{\prime}$, happen at the same time according to them, namely $t_{1} \cdot{ }^{23}$ However, in the diagram, a third person, $c$, moving uniformly at a very high speed relative to $a$ and $b$, towards them along their $x$-axis, is also depicted (I consider a futuristic sci-fi scenario with the purpose of making a philosophical point). Person $c$ 's planes of simultaneity are at an angle to $a$ 's and $b$ 's planes of

\footnotetext{
21 I follow Schaffer (2009, forthcoming) in allowing the relata of grounding to belong to different categories of being, i.e. they need not be facts.

${ }^{22}$ In some reference frames, the relevant grounding relation will be directed forward in time, which is not as counterintuitive as backward grounding but which nevertheless violates the simultaneity requirement.

23 Of course, the student will not know that the grading has occurred until sometime later, when a causal signal about the content of the grading has reached her; but at the later time she can deduce that the grading occurred at $t_{1}$ and that she therefore acquired the grade at $t_{1}$ (given the assumption that the acquisition of the grade is, in her reference frame, synchronically grounded in the grading).
} 


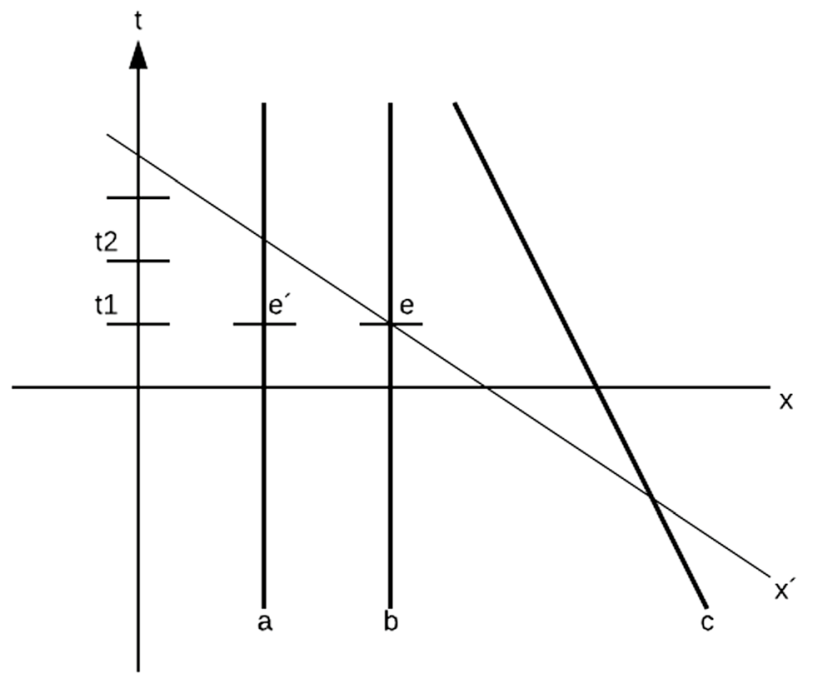

Fig. 1 Events e and e' do not occur simultaneously according to observer c. Specifically, e' occurs before e in c's frame of reference. (y- and z-dimensions, and light-cone structures, are not displayed in the diagram)

simultaneity. In particular, according to $c$, event $e^{\prime}$ occurs before event $e$ ! But if $e^{\prime}$ depends on $e$, then $e$ 's grounding or generation of $e^{\prime}$ is directed backward in time in $c$ 's reference frame. Such a scenario, involving backward grounding of a real, worldly institutional property, will, I take it, be generally rejected by social ontologists ${ }^{24}$ : how could a person or object, relative to a certain frame of reference, acquire a worldly institutional property before the relevant declaration has occurred? Such backward grounding seems almost as weird as backward causation. Certainly, scenarios like this will be rejected by anyone who, like Searle, is already committed to the simultaneity requirement. ${ }^{25}$

\footnotetext{
${ }^{24}$ Admittedly, Schaffer is probably an exception: he proclaims that "there is no problem whatsoever in positing 'non-local' grounding connections across space and time" (forthcoming). But I think many will find backward grounding of real, worldly properties a highly troublesome and counterintuitive notion. I should also mention in this connection that Brian Epstein holds that his "framing relations" (which are not grounding relations, according to him) between rules (or "framing principles") and worldly institutional facts apply across times and even worlds (2015: pp. 77-78, 123-124); but he never explains how this could be the case.

${ }^{25}$ Searle's notion that declarations have a "double direction of fit" arguably also breaks down—or ceases to have application across reference frames-in a scenario like this. If, according to observer $c$, the student $a$ already has acquired the worldly institutional feature when the declaration occurs, then $b$ 's declaration appears to have merely a word-to-world direction of fit, $\downarrow$, in $c$ 's reference frame (even if the declaration, in c's reference frame, also allegedly grounds the pre-existing state of affairs, backward in time). Similarly - although the other way round - for someone moving in the opposite direction at high speed: since the relevant worldly institutional state of affairs is, in this reference frame, created after $b$ 's declaration, arguably $b$ 's declaration has merely a world-to-word direction of fit, $\uparrow$, in this frame of reference. (Compare: according to Searle, commissives and directives have merely a world-to-word direction of fit, $\uparrow$, even if they, in a sense, both describe and generate the intended future state of affairs. See Sect. 2 above).
} 
To avoid (relative) backward (but also forward, see notes 22 and 25) grounding of worldly institutional facts, a defender of an ontological dependence account will have to insist, against STR, that $e$ and $e^{\prime}$ are simultaneous in all reference frames (i.e. relative to all observers, including $a, b$ and $c$ ). A natural way of defending such a view would be to say that we inhabit a Newtonian spacetime with absolute simultaneity relations, and maintain (in line with the reasoning of Prior 1996/1998; Craig 2000, Ch. 5; Tooley 1997, Ch. 11; Craig and Smith 2008) that the relative simultaneity planes of STR are mere artefacts of certain contingent, operational definitions of temporal and spatial intervals, and account for the classical Michelson-Morley and the Kennedy-Thorndike experiments (which support the notion that the speed of light is a constant) in terms of absolute clock retardation and absolute shrinking of measuring rods, in the manner pioneered by Hendrik Lorentz (see his papers in Einstein et al. 1952).

Such a view is very unattractive. As is well known, to date no satisfactory explanation of why physical processes slow down (absolutely) and material objects contract (absolutely) when moving relative to the absolute rest frame, assuming such a frame exists, has been provided. Without such an explanation, the Newtonian/Lorentzian theory looks seriously ad hoc. By contrast, the purely relative time dilations and length contractions of STR follow from the postulates of the theory (see Sklar 1974, Ch. IV, B for discussion of the rival theories of Lorentz and Einstein).

A further problem, and one that applies specifically to the issue of institutional reality, is as follows. Defenders of a grounding account who insist that events such as $e$ (i.e. declarations made by humans on earth) and $e^{\prime}$ (the changes created by such declarations) are not only relatively but absolutely simultaneous are apparently committed to the notion that earthlings are absolutely at rest relative to absolute space (at least approximately, or for brief periods of time, so that Earth's rotation around its axis can be ignored), although there is no way of empirically confirming that such a situation obtains, due to absolute time dilations and length contractions. ${ }^{26}$ Earth's being at rest relative to absolute space would seem to be an extraordinary coincidence in need of explanation and theoretical support. It cannot be simply assumed. ${ }^{27}$

In short, the Newtonian understanding of space and time is both archaic and introduces added explanatory burdens and complications. With this in mind, I will

\footnotetext{
${ }^{26}$ Of course, if acquisitions of status functions were themselves directly empirically detectable-e.g. if status functions brought new physical causal powers to their subjects - then, assuming their "creation" is absolutely simultaneous with the declarations that create them, their detection could be used to deduce the absolute rest frame and the absolute simultaneity relations; and then we would know whether or not Earth is at rest in absolute space. But obviously, acquisitions of status functions are not directly empirically detectable — at best, they are indirectly "detectable" through the receipt of information (via normal, finite-speed, causal signals or processes) about the relevant declaration having taken place.

27 On the face of it, within a Newtonian/Lorentzian framework, it is more probable that we earthlings are in a situation in which our relative simultaneity relations do not coincide with the absolute simultaneity relations - because Earth is moving relative to absolute space, perhaps at a very high speed-so that events such as $e^{\prime}$ happen (in relative, earthly time) either after or before the declarations which, in absolute time, synchronically generate them, depending on how Earth moves relative to absolute space.
} 
assume from here on that the absolute simultaneity option is not on the table for Searleans. Moreover, the issue of the relevant generative mechanism would be left unresolved within such a framework. ${ }^{28}$

The lesson of the discussion in this section, then, is not that STR is false. Nor, in my view, should we conclude that the relevant results of Status Function Declarations are effects or events that happen absolutely after the declarations, i.e. within the future light cone of the relevant declarations. For while that view would be compatible with STR, it would violate Searle's simultaneity requirement-an intuitively plausible thesis which I think should be retained, in some form or another, if possible. ${ }^{29,}{ }^{30}$ Thus, I think the most plausible conclusion of the foregoing discussion is that Status Function Declarations do not genuinely change anything in the world (the agreed physical and mental changes apart): such declarations bring nothing "extralinguistic" into existence; they do not create institutional properties, or institutional objects; they do not create worldly institutional facts. The acquisition of a grade by a student, for example, is not a genuine event, taking place at a certain location; it does not involve a genuine change in a subject.

\section{Mere Cambridge change and institutional truths}

If the acquisition of a grade is not a genuine event, what is it? Students do, after all, acquire grades - that can hardly be denied. I shall argue that acquisitions of (putative) institutional features or properties ("status functions") should be thought of as so-called "mere Cambridge events" (cf. Kim 1974: p. 48). Such events involve "mere Cambridge change": a monadic predicate becomes applicable (or ceases to be applicable) to an object in virtue of changes that happen elsewhere. The "creation" of full institutional objects, I shall argue, should be understood in similar terms: existential, institutional statements or propositions become true (if present-tensed), but the truth-makers for such truths do not involve ontic institutional objects existing in the world.

The term "mere Cambridge change" was coined by Peter Geach in his book God and the Soul (1969), where he discussed the following Cambridge criterion of

\footnotetext{
28 Thus, I wholeheartedly agree with Nikk Effingham (2010: p. 253) when he says: "I think it is strange that merely speaking and intoning certain phrases could cause [or ground] anything to exist (except, of course, for the words and intonations themselves). [...] The thought is that only wizards and warlocks can bring things into existence by merely uttering a few phrases." See also Zimmerman (2002: pp. 333334), and Smit and Buekens (2017: p. 240).

29 In Sect. 4, I address some possible exceptions to the simultaneity thesis - but these will turn out to be quite harmless on my preferred "mere Cambridge change" account.

30 Note that if a simultaneity view is accepted, so-called "social mechanisms" accounts (e.g. Hindriks 2017) cannot be defended by institutional realists as problem-solvers: such accounts explicitly involve causal processes propagating at slower-than-light speed (thanks to an anonymous reviewer for suggesting such accounts as potential problem-solvers). Nor can Smit and Buekens's (2017) deflationary "incentivization" account be endorsed as a fully satisfactory account of declarations (although I agree with much of what is said in this paper), since it too relies on causal processes (e.g. pp. 244-245); thereby it denies that declarations can synchronically yield institutional truths.
} 
change, based on the work of Bertrand Russell and Ellis McTaggart (e.g. Russell 1903: p. 469; McTaggart 1927: p. 14):

The thing called " $x$ " has changed if we have " $\mathrm{F}(x)$ at time $t$ " true and " $\mathrm{F}(x)$ at time $t^{1}$ " false, for some interpretation of " $F$ ", " $t$ ", and " $t$ ". (Geach 1969: pp. 71-72)

Geach pointed out that this criterion gives the odd result that a person $a$ "changes" when she comes to be shorter than another person $b$ in virtue of the latter's growth. For a monadic predicate, "is shorter than $b$ ", becomes true of $a$ having not been true of $a$ at an earlier time. This is not a genuine or real change in the person $a$, according to Geach: it is a mere Cambridge change. The predicate "is shorter than $b$ " comes to apply to $a$ solely as a result of a genuine change that happens to someone else, $b$, somewhere else (see also Kim 1974; Shoemaker 1980/1997; Mellor 1998: pp. $87-88) .^{31}$

This diagnosis applies quite straightforwardly, I think, to the cases where an institutional property (or "status function") is imposed on, or ascribed to, a pre-existing object (cf. Searle 2010: p. 99). Consider our example of grading again. An examiner declares, at a certain place, and at a certain time (relative to, say, his own frame of reference), that student $a$ has acquired grade $\mathrm{Y}$ in subject $\mathrm{S}$. The examiner's act of writing or typing is a genuine change in the world, with a location. Given that the examiner is duly authorized, ${ }^{32}$ and as long as the relevant rules and requirements regarding grading have been followed, an institutional predicate ${ }^{33}$ of the form "has acquired grade $\mathrm{Y}$ in subject $\mathrm{S}$ " becomes true of student $a$-and it does so irrespective of $a$ 's whereabouts. Since this predicate is now true of the student (in the

\footnotetext{
${ }^{31}$ Note also that the two-place predicate "is shorter than" (contrast the monadic predicate "is shorter than $b$ ") is typically regarded as a predicate which expresses a mere "internal relation" (see e.g. Armstrong 2004: p. 50): the predicate applies in a certain case not in virtue of the existence of an ontic shorter-than relation instantiated by objects $x$ and $y$, but in virtue of the way $x$ and $y$ themselves are-i.e. in virtue of their respective spatial extensions. Also, the truth-making relation holding between some suitable portion of the world and a true contingent statement of the form " $a$ is $F$ " (or proposition of the form $\langle a$ is $F>$ ) is arguably an internal relation: given the statement's content and the existence of the relevant portion of the world, the statement is thereby made true (for defenses of truth-making as an internal relation, see e.g. Armstrong 2004: pp. 9, 50; Heil 2012: pp. 156, 160-162). In a similar manner, it seems plausible to hold that a statement of the form "the predicate ' $F$ ' applies to object $a$ " (or a proposition of the form <the predicate ' $F$ ' applies to object $a>$ ) is made true simply by the meaningful predicate and some suitable portion of the world of which the relevant object $a$ is a part-the truth-maker need not also involve some external applying-relation (or satisfying-relation) holding between the meaningful predicate and object $a$. If this is correct, then an occurrence of mere Cambridge change need not even involve the coming into existence of some external ontic relation.

32 That is, given that the predicate "is authorized" applies to the person for reasons similar to those described in the text regarding how the predicate "has acquired grade Y" applies to the student. It is difficult to account for all the apparent status functions in terms of mere Cambridge change in a single go. Thus, I am not here attempting to provide a reductive analysis of "has acquired grade Y"; rather I am trying to paint a picture of what goes on ontologically when someone acquires a grade. The idea, of course, is that similar considerations apply to other putative cases of status function impositions: they involve, not genuine creations and changes, as Searle and others apparently claim, but mere Cambridge changes.

${ }^{33}$ Alternatively, we can put the idea in terms of a concept which becomes applicable to the student, or which is such that the student begins to fall under it.
} 
examiner's reference frame), it can be truly said that the student has, from this time onwards, a new institutional "status". She is now entitled to enroll on a new course, etc. It can even be said that the student has acquired a new institutional property, as long as "property" is understood merely in the weak, abundant sense discussed by philosophers such as Lewis (1986a: pp. 59-60), Mellor (1995: pp. 157-159, 185), Bird (2007: pp. 9-12), and Heil (2012: pp. 23-24), according to which, roughly, an object $x$ has a "property" $F$ if predicate " $F$ " applies to $x .{ }^{34}$ What the student has not acquired, however, is a property in a strong, sparse (or ontic) sense (ibid.): nothing actually happened to the student or in the student's whereabouts. In this sense, the acquisition of the grade is not a genuine event, but a mere Cambridge event involving mere Cambridge change.

If "acquisition" of a grade is a mere Cambridge event, the difficulties with STR vanish. No causal process propagates from the declaration to the student at a speed faster than light; no sparse, ontic institutional property of the student, located within the absolute elsewhere of the declaration, gets grounded by the declaration. ${ }^{35}$ Rather, a mere predicate becomes true of the student, as a result of the declaration. The predicate, moreover, can be taken to become true of the student at the time of the declaration-i.e. simultaneously with the declaration-in all reference frames without any need to postulate absolute simultaneity relations. In the reference frame of the student and the examiner, the predicate "has grade $\mathrm{Y}$ " becomes true of the student at time $t_{1}$ (although the student may not be aware of this at $t_{1}$ ) (see Fig. 1); but in the reference frame of observer $c$, the predicate can be taken to become true of the student at the simultaneity plane indicated by the drawn $x^{\prime}$-axis in Fig. 1. This scenario does not involve the paradoxical situation that there is a single, genuine event $e^{\prime}$ ( $a$ 's acquisition of the grade Y) that succeeds in being located at two distinct places in spacetime (see Fig. 2) — which, of course, would be impossible.

Rather, the claim is that no genuine event $e^{\prime}$ occurs at all. This more modest interpretation simply involves the notion that "the acquisition of the grade $\mathrm{Y}$ " is to be understood in terms of a predication which is relativized, or indexed, to a reference frame with its own planes of simultaneity or times (see Fig. 3).

\footnotetext{
34 Strictly speaking, Lewis understands abundant properties in terms of set-theoretic constructions of objects (ibid.).

35 For the record: I think such a view should be avoided even if grounding is taken to be an internal, or even superinternal, relation (cf. Bennett 2011). The notion that a sparse, ontic, worldly institutional property (or object or fact) can be grounded by a Status Function Declaration is simply fantastic, irrespective of the ontic status of the grounding relation itself. Note, however, that sometimes grounding is characterized as an external relation (e.g. Schaffer 2009: pp. 354-355, 372), i.e. as a relation which is an "entity" over and above its relata-somewhat analogously to how causation is standardly taken to be an external relation. On such a view of grounding, the putative grounding of institutional facts becomes even more troublesome, especially within a relativistic context. Also, observe that if grounding is an external relation, then truth-making cannot plausibly be held to be a species of grounding (as is suggested, e.g., by Schaffer 2010), because truth-making is arguably an internal relation (see note 31 above). For further discussion of the problems with analyzing truth-making in terms of grounding, see Tahko (2013) and Griffith (2014).
} 


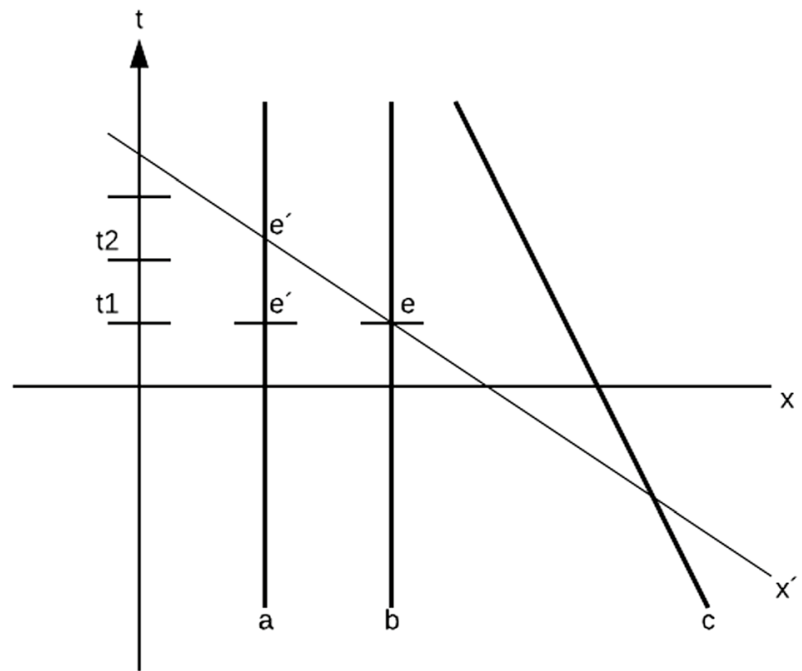

Fig. 2 One and the same event, e', is depicted as being located twice over in spacetime

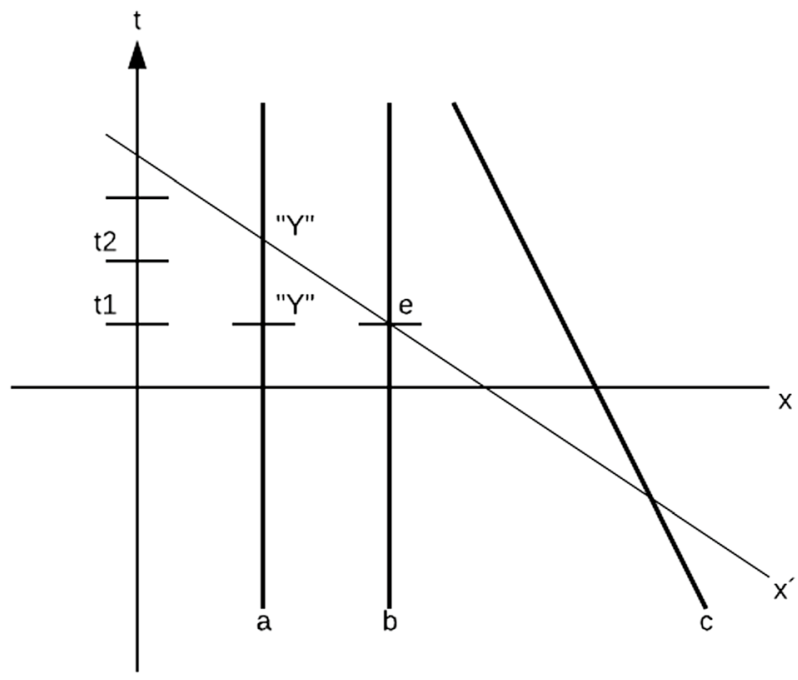

Fig. 3 The predicate "has grade Y" becomes true of a, because of b's declaration e, at distinct simultaneity planes of spacetime, according to a and $b$, and $c$, respectively

Similar considerations apply, I submit, to other impositions of putative status functions to pre-existing objects through declarations: to someone's appointment as president, promotion to a professorship, or sentencing to a term in prison. ${ }^{36}$

\footnotetext{
${ }^{36}$ Thus, if sci-fi scenarios involving high-speed interstellar travel ever become a reality, regulations will need to specify what frame of reference should take precedence in cases involving persons and objects moving at high speed relative to each other, on pain of future individuals having to face irresolvable legal controversies.
} 
This mere-Cambridge-change account also enables us to make sense of the special cases where declarations are directed towards the past from the point of view of the one who is performing the declaration. ${ }^{37}$ Consider grading yet again. In the Swedish university system (and in the Dutch, I am told), grades are often assigned retrospectively: a student completes an assignment on a certain date $t$, but a busy professor grades the assignment at a later date $t^{\prime}$ and in so doing gives the student an official grade which is valid from the earlier time $t$ onwards. If something was really created at $t$ by the declaration at $t^{\prime}$, we would have a case of backward causation or grounding - but this time, within the past light cone of the declaration (i.e. within the so-called absolute past of the declaration, entailing that the acquisition of the grade occurs before the declaration in all reference frames). By contrast, on the mere-Cambridge-change view a mere predicate of the form "has grade Y" becomes true of the student, in virtue of the declaration at $t^{\prime}$. The student does not genuinely change as a result of the declaration. Interestingly, though, on the assumption that the B-theory of time is correct-according to which all events (i.e. events deemed "future", "present" or "past" from the point of view of someone existing in spacetime) are equally real ${ }^{38}$ - the present-tensed predicate "has grade $\mathrm{Y}$ " is true of the student already at time $t$, owing to the existence of the later, past-directed declaration at $t^{\prime}$. However, at $t$ the declaration is epistemologically inaccessible to everyone, so at that time no one acts on its "consequences"; but the institutional predicate is nevertheless true of the student at $t$, on this worldview. ${ }^{39}$ Thus, the genuine change or event (i.e. the making of the relevant past-directed declaration) occurs at time $t^{\prime}$, and the "result" of that event is a mere Cambridge change concerning a predicate which, on the B-theory of time, is true of the student at $t$ and onwards, but not at times before $t$. After $t^{\prime}$, of course, the declaration gradually becomes epistemologically accessible to the relevant society at large, and people, including the student, start behaving in accordance with it (cf. Sect. 5 below).

So far, I have been discussing the imposition of an institutional property or "status function" to a pre-existing physical object. I have not yet addressed the alleged creation of institutional objects such as corporations (i.e. instances of so-called freestanding Y-terms) through Status Function Declarations. ${ }^{40}$ About this second variety of institutional creation, Searle writes:

\footnotetext{
37 Thanks to Frank Hindriks for drawing my attention to this interesting phenomenon, which is neglected by Searle. Hindriks would not agree with my account of the phenomenon, though (see Hindriks, ms).

${ }^{38}$ The special theory of relativity seems to require the truth of the B-theory of time-see Putnam (1967) for an influential argument for this conclusion. For further discussion and references, see Mellor (1998), Sider (2001) and my (2009).

${ }^{39} \mathrm{I}$ assume here that during the time span in question people in the relevant society accept "standing declarations" with general content, authorizing the professor's grading, in line with what is said in footnotes 6 and 19 above.

${ }^{40}$ Elsewhere (Hansson Wahlberg 2014a), I have argued that, strictly speaking, a physical object or person $\mathrm{X}$ who comes to satisfy an institutional sortal predicate $\mathrm{Y}$ can also be said to be an "institutional object". Here, however, I reserve the term for the so-called free-standing-Y-term cases (e.g. Searle 2010: p. 98).
} 
In this case we seem to have created a remarkably potent object, a limited liability corporation, so to speak out of thin air. No pre-existing object was operated on to turn it into a corporation. Rather, we simply made it the case by fiat, by Declaration, that the corporation exists. (Searle 2010: p. 98) ${ }^{41}$

I think the idea that an object is literally created in this way needs to be avoided. It is better to adapt the mere-Cambridge-change account of institutional properties and apply it to objects. On this account, a declaration to the effect that a corporation exists is made, and because of this declaration it becomes true to say, in a tensed language and within a suitable reference frame, "A corporation, founded in such and such a way, exists". ${ }^{42}$ The truth-maker for such an existential assertion, however, should not be taken to be a new, ontic, institutional object that is somehow brought into existence in the world (perhaps, at its "institutional location", cf. Hindriks 2013: p. 418) simultaneously with the declaration. That would lead to difficulties of the kind discussed above. Rather, the truth-maker (or truth-makers) should be assumed to consist simply of the declaration itself, together with representations of the relevant legal regulation. ${ }^{43}$

In effect, I am suggesting that the institutional object case is in an important respect similar to many of the so-called deflationary cases discussed in the truthmaker literature (e.g. Armstrong 2004: p. 33). These involve existential statements which are made true by entities ostensibly quite different from the entity claimed to exist. For example, Hugh Mellor (2012: pp. 98-99) argues that true existential propositions about rainbows, such as <there is a rainbow east of car $c$ driving north>, are not made true by peculiar rainbow-entities with remarkable properties (in the example in question, a rainbow that keeps pace with $c$ as it moves north); they are made true by sunlight-reflecting raindrops. Similarly, David Armstrong (2004: pp. 137-142) argues that true existential propositions about dispositions are made true by categorical properties governed by contingent laws of nature, not by ontic dispositions or so-called powers. And John Heil (2012: pp. 19, 153-155; forthcoming) argues that propositions (or "judgments") about macroscopic objects are made true by micro particles appropriately arranged, not by macro-objects. ${ }^{44}$ Similarly, my suggestion is that existential propositions or statements concerning corporations,

\footnotetext{
41 Searle quotes the California Code regarding corporations in support of his view: "Section 200A: 'One or more natural persons, partnerships, associations or corporations, domestic or foreign, may form a corporation under this division by executing and filing articles of incorporation.' Section C: 'The corporate existence begins upon the filing of the articles and continues perpetually, unless otherwise expressly provided by law or in the articles"' (Searle 2010: p. 97, italics original).

42 At least, it is true to say this up to the time of the corporation's "termination", which often consists in another declaration. Using a tenseless language_-in which "exists" means, roughly, "existed, exists now, or will exist" - it will be true to say this at any time, assuming the B-theory of time is correct. The truthmaker(s) can then be located in some past, present or future region of spacetime, from the point of view of the time of the statement.

43 Perhaps the truth-maker should be expanded to include other circumstances as well, such as the history of the founders, etc. The key point is that it should not be taken to consist of a new entity which is somehow brought into existence in the world simultaneously with the declaration.

44 I am not necessarily endorsing all of these non-institutional examples. I am merely using them to illustrate the main idea.
} 
and other institutional objects, are not made true by ontic institutional objects, but by declarations and other human activities and representations. ${ }^{45}$

All in all, I think it is deeply problematic (and certainly highly misleading, if Searle does not want his claims to be taken literally) to maintain that we have an "amazing" or "quasi-magical" ability to "create" institutional facts-non-identical with mental states and true propositions- "corresponding" to the content of extralinguistic declarations. Rather, we should simply maintain that in virtue of the declarations, predicates that formerly did not apply to a certain object or set of objects come to apply to the object or sets of objects; and that in virtue of the declarations it becomes possible to quantify over institutional objects, at least in certain types of discourse. ${ }^{46}$ Thus, saying so can indeed make it so, as Austin (1962: p. 7) originally taught us; but not because declarations create worldly, extralinguistic, institutional facts corresponding to their propositional contents, but rather because declarations "create" institutional truths and are themselves one of the truth-makers for those truths. With some provisos (see below), it would appear that Searle is in the grip of a misunderstanding: he seems to think that institutional truths must be made true by extra-linguistic institutional facts.

I want to end this section by acknowledging that, in spite of numerous formulations suggesting the contrary, Searle might in the end agree with my core ontological point that nothing is really created in the world when we perform Status Function Declarations. In The Construction of Social Reality (1995) and Making the Social World (2010), Searle says that institutional features are "ontologically subjective" (1995: p. 10, 2010: p. 18) because they are "intentionality-relative" (2010: p. 17) or "observer-relative features of the world" (1995: 9 ff.). In Speech Acts (1969: pp. 103-106), he defends a version of predicate nominalism with regard to the ontology of properties (cf. Armstrong 978: pp. 12-14). Clearly, a predicate nominalist account of putative institutional properties would combine very well with the mereCambridge-change view defended above. ${ }^{47}$ Also, in Speech Acts (1969: p. 52) and in The Construction of Social Reality (1995: p. 28), Searle puts a lot of emphasis on the role of constitutive rules of the form "X counts as $\mathrm{Y}$ " in the "construction" of institutional "reality". Saying that something X counts as a Y sounds a lot more

\footnotetext{
45 At this point, the reader might worry: Are not speech acts such as declarations a kind of institutional phenomenon generated by constitutive rules (cf. Searle 1969)? If so, how can they be (constituents of) truth-makers? My answer: it may indeed be that we should take the ultimate truth-makers here to be utterances or inscribings of words (cf. Austin's "phatic acts", 1962: p. 95) and various representations of semantic rules, but I think the main arguments and conclusions of the present paper can be set out without settling this specific issue. In the paper I also wish to remain uncommitted on how language itself works. (For Searle's take on the difference between the generation of illocutionary acts and extralinguistic institutional reality, see his 2010: pp. 14, 110-115).

46 That is, in ordinary, legal and social science discourse, but arguably not when advancing metaphysical existence claims, in a discourse about truth-makers, conducted in Ontologese, as it were (cf. Mellor 2012: pp. 99-100; Heil 2012: pp. 165-167; Sider 2011: p. 171).

47 The predicate nominalism endorsed in Speech Acts is defended as a doctrine about properties in general, not as a doctrine restricted to institutional properties. By contrast, I have merely been arguing that creation of institutional "properties" is best understood on the model of mere Cambridge change. Searle does not discuss mere Cambridge change.
} 
innocent - especially within predicate nominalism — than saying "in the nonlinguistic Status Function Declaration, we do more than represent: we create" (Searle 2010: p. 114), or "We (or I) make it the case by Declaration that the Y status function exists" (ibid: 101). I also want to point out that in Making the Social World, Searle remarks, in passing, about corporations, that:

...we need to specify not just that the [status] function exists but that there is an entity $\mathrm{Y}$, the corporation, that has the function, even though the entity is, as they say, a "fictitious" entity. [...] On the standard accounts of the semantics of quantificational logic, the quantifiers range over a domain of existing objects. But in the case of the creation of entities that have status functions, there is no such domain. (Searle 2010: pp. 100, 120) ${ }^{48}$

Moreover, in The Construction of Social Reality, Searle denies that the "correspondence" in the correspondence theory of truth-a theory which Searle defends in Ch. 9 of the book-needs to involve "resemblance" or "isomorphism" between statements and facts (1995: pp. 213-214).

It is unclear what we should make of these claims and doctrines, however. To say that something is intentionality-relative or mind-dependent, or even ontologically subjective, is not necessarily to say that it does not belong to the furniture of the universe and does not really exist. Jonathan Schaffer (2009), for example, argues that ontologically dependent or grounded entities-mind-dependent entities included (ibid: 362) — are as real or existent as the entities they depend upon. Searle himself says, about pains and intentions, that they are "ontologically subjective" in that "they exist only as experienced by human or animal subjects" (Searle 2010: p. 18), but he nevertheless maintains that mental states are "features of reality" (Searle 1995: p. 12). And, crucially, if saying that something is ontologically subjective is to say that it does not really exist, how could institutional facts, being held to be ontologically subjective, be said to be truth-makers for institutional truths (e.g. Searle 1995: p. 221)? Relatedly, how could Status Function Declarations with their putative double direction of fit, $\uparrow \downarrow$, ever be successful in Searle's view, if the allegedly fitting relata at the other end, the institutional facts created, were strictly speaking non-existent?

Moreover, it is unclear whether Searle is still a predicate nominalist: as far as I know, he has not defended predicate nominalism since Speech Acts (1969) and has never mentioned predicate nominalism in connection with status functions. In Making the Social World (2010), he has also made it clear that he now thinks the theory of Status Function Declarations is the fundamental theory of the "construction" of institutional reality: constitutive rules are to be interpreted as various forms of "standing declarations" with double direction of fit (e.g. Searle 2010: pp. 13, 97). Constitutive rules of the paradigmatic form " $\mathrm{X}$ counts as $\mathrm{Y}$ in $\mathrm{C}$ " are played down: Searle maintains that we can create status functions without there being a brute

\footnotetext{
48 And in his (2014: p. 20; see also 1995: p. 36; 2003: pp. 302-303), Searle maintains: "'Objects' that figure in Institutional Facts are typically placeholders for patterns of activity. Think of corporations, money, and vacations." (Thanks to an anonymous reviewer here).
} 
object X which is counted as a Y (i.e. in cases of free-standing Y terms; e.g. Searle 2010: pp. 20-21, 97-102).

Complicating matters further, although Searle occasionally describes institutional objects such as corporations as fictitious entities, he also explicitly maintains, as we have seen, that they are "created" and that we make this the case by declarations that they "exist" (Searle 2010: pp. 120, 122). ${ }^{49}$ And although he says that he is not committed to correspondence as isomorphism, he does at various places claim that facts are what make true statements true (e.g. 1995: pp. 211, 221), that facts have a "structure" (1995: 221), indeed "a propositional structure" (2014: p. 20), and that facts "have to be propositionally specified" (1995: p. 212), or alternatively, "can only be stated and not named" (1995: p. 211). All of which strongly suggests that facts have an object-property structure somehow mirroring the subject-predicate structure of the statements or propositions that specify them and are made true by them.

Concerning institutional facts, he explicitly says:

Once you see the power of the Declaration to create an institutional reality, a reality of governments, universities, marriages, private property, money, and all the rest of it, you can see that social reality has a formal structure as simple and elegant as the structure of the language used to create it. (Searle 2010: p. 16, my emphasis)

Such remarks strongly suggest that a Status Function Declaration, whose propositional content is of the form " $a$ is $F$ ", brings into existence a corresponding and structurally similar institutional fact, a fact of the form $a$ 's being $F$, where $F$ is an institutional property.

Be this as it may. If, appearances to the contrary, Searle is defending nothing more than a mere-Cambridge-change account of the creation or imposition of "status functions", if he is, more generally, wedded to no more than the notion that our declarations create institutional truths, not corresponding worldly institutional facts or states of affairs, then this paper can be seen as a friendly plea to him (or to his followers) to explicitly formulate the theory in such more modest terms.

\section{What follows?}

If nothing is created by Status Function Declarations except institutional truths, what follows? One important implication concerns causation. If the institutional properties, objects and facts allegedly created by declarations do not exist in a worldly sense, they cannot be relata of causal relations (or any other relations for that matter). Yet, we often speak as if such properties/objects/facts have a causal

\footnotetext{
49 Searle also says that persons can stand in various relations to status functions, free-standing status functions included: "We (or I) make it the case by declaration that a Y status function exists in C and in doing so we (or I) create a relation $\mathrm{R}$ between $\mathrm{Y}$ and a certain person or persons, $\mathrm{S}$, such that in virtue of SRY, S has the power to perform acts (of type) A" (ibid.: 101-102; see also p. 98). Prima facie, the existence of relations requires the existence of relata, such as corporations. Searle does not qualify his claims by saying that he merely talking about true statements about corporations and their relations.
} 
impact or partake in causal processes. We do so in everyday speech ("His poor grades caused him to lose his scholarship", "Money causes more harm than good", "...this was caused by the fact that the company had..." etc.); and the academic literature (in philosophy, sociology, political science, etc.) is replete with such institutional causal claims. ${ }^{50}$ And Searle, as we have seen, sometimes seems to suggest that institutional facts and status functions are causally potent: "facts [in general, institutional facts included] function causally in a way that true statements do not" (1995: 206), and "a function [status functions included] is a cause with a purpose" (2006: p. 17, 2010: p. 59). But again, if status functions and institutional facts do not really exist as worldly entities, they cannot be causes. ${ }^{51}$ At least, they cannot be what we might call "sparse causes" (in analogy with the distinction between sparse/ ontic and abundant/predicate-nominalistic properties, see Sect. 4 above). A sparse cause, let us say, is an ontic entity that is a relatum of an ontic causal transaction or process of some kind. A “mere abundant cause", let us stipulate, figures as a (putative) cause in a true causal statement, without being a sparse cause. To illustrate: it is sometimes argued that causal statements involving "absences" and "omissions" as causes can be true, although absences and omissions do not exist as worldly or ontic entities (e.g. Mellor 1995, Ch. 13; Dowe 2000, Ch. 6; Lewis 2000/2004: pp. 99-102; Woodward 2003: pp. 86-91); on such a view, absences and omissions fall out as mere abundant causes, according to the terminology suggested here. ${ }^{52}$ Similarly, one could maintain - in an attempt at rescuing some watered-down form of institutional causation - that institutional properties/objects/facts can figure as mere abundant causes in true, institutional, diachronic causal statements (such as "His poor grades caused him to be depressed", "...caused him to lead a miserable life", etc.). But importantly, if what I have been arguing is correct, the truth-makers for such causal statements (assuming they are true) will not involve institutional properties/objects/facts. ${ }^{53}$ Rather, the key truth-makers will in many cases, in all likelihood, involve (although certainly not exhaustively) people's mental representations of institutional properties/objects/facts (see also my forthcoming). Nothing about what I have said rules out that representations of institutional entities can be sparsely

\footnotetext{
${ }^{50}$ For some recent, metaphysically loaded, examples, see Elder-Vass (2010), Lawson (2013), and Little (2016). (Apart from suffering from the kind of difficulties outlined above, these examples are problematic in that they involve troublesome notions of intrastructuration, extrinsic positional power, emergence, social structure, and downward causation, and in many cases conflate deontic powers with causal powers; for detailed, critical discussion, see my 2014b, c and forthcoming).

51 It is often argued that extrinsic properties and events cannot partake in causation (Kim 1974; Shoemaker 1980/1997; Lewis 1986b: pp. 163-264). Here I am applying the argument to institutional features, and I am, in a way, strengthening it by arguing that institutional properties, objects and events (generated by declarations) are not merely extrinsic; they do not even exist (in the truth-maker sense).

${ }^{52}$ Note that it is conceptually possible for there to be mere abundant causes that fail to be sparse causes because they do not, on the occasion in question, partake in an ontic causal transaction or processes, even though they exist in the truth-maker sense. However, there is little reason to assume the existence (in the truth-maker sense) of entities that never partake in ontic causal transactions or processes.

53 Cf. Mellor (1995, Ch. 15) who argues that the truth-makers for true causal propositions are often quite different from what they appear to be.
} 
causally efficacious and influence the way that people feel, reason and behave. ${ }^{54} \mathrm{~A}$ detailed positive account of these causal issues will have to wait for another occasion, however. ${ }^{55}$

Acknowledgements Open access funding provided by Lund University. Earlier drafts of this paper were presented at the Higher Seminar in Theoretical Philosophy at Lund University (November 2018), at the Swedish Congress of Philosophy at Umeå University (June 2019), and at the ENSO VI: Social Ontology conference at Tampere University (August 2019). Many thanks to the audiences for valuable feedback. Special thanks to the two anonymous reviewers for Synthese for their helpful comments and constructive criticisms. Finally, I am very grateful to Robin Stenwall and Lena Wahlberg for valuable discussions. The writing of the paper was funded by Riksbankens Jubileumsfond, Grant Number P15-0744:1.

Open Access This article is distributed under the terms of the Creative Commons Attribution 4.0 International License (http://creativecommons.org/licenses/by/4.0/), which permits unrestricted use, distribution, and reproduction in any medium, provided you give appropriate credit to the original author(s) and the source, provide a link to the Creative Commons license, and indicate if changes were made.

\section{References}

Anscombe, G. E. M. (1958). On brute facts. Analysis, 18(3), 69-72.

Armstrong, D. M. (1978). Universals \& scientific realism, Vol. 1: Nominalism \& realism. Cambridge: Cambridge University Press.

Armstrong, D. M. (1997). A world of states of affairs. Cambridge: Cambridge University Press.

Armstrong, D. M. (2004). Truth and truthmakers. Cambridge: Cambridge University Press.

Austin, J. L. (1950/1979). Truth. In Philosophical papers, 3rd edn (pp. 117-133). Oxford: Oxford University Press.

Austin, J. L. (1956/1979). Performative utterances. In Philosophical papers, 3rd edn (pp. 233-252). Oxford: Oxford University Press.

Austin, J. L. (1962). How to do things with words. Cambridge: Harvard University Press.

Baker, L. R. (2007). The metaphysics of everyday life. Cambridge: Cambridge University Press.

Bennett, K. (2011). By our bootstraps. Philosophical Perspectives, 25, $27-41$.

Bernstein, S. (2016). Grounding is not causation. Philosophical Perspectives, 30, 21-38.

Bird, A. (2007). Nature's metaphysics: Laws and properties. Oxford: Oxford University Press.

Blackburn, S. (2010). Whatever you say. In The new republic, July 2010 Retrieved Feb 16, 2011 from https://newrepublic.com/article/76092/whatever-you-say.

Craig, W. L. (2000). The tenseless theory of time: A critical examination. Dordrecht: Kluwer Academic Publishers.

Craig, W. L., \& Smith, Q. (Eds.). (2008). Einstein, relativity and absolute simultaneity. London: Routledge.

Dowe, P. (2000). Physical causation. Cambridge: Cambridge University Press.

Effingham, N. (2010). The metaphysics of groups. Philosophical Studies, 149(2), 251-267.

Einstein, A., et al. (Eds.). (1952). The principle of relativity. Mineola: Dover Publications.

Elder-Vass, D. (2010). The causal power of social structures: Emergence, structure and agency. Cambridge: Cambridge University Press.

\footnotetext{
${ }^{54}$ Cf. Searle (2001, Ch. 6), although Searle focuses on external reasons for action.

55 For now, I wish to be noncommittal about, for example, the exact nature of ontic causal transactions (i.e., whether they should be understood in terms of conserved quantities, forces, manifestations of powers, counterfactual dependencies between predominantly intrinsic events, etc.) and whether ordinary causal statements can be reductively analyzed (e.g., in terms of diachronic counterfactual statements about (putative) entities).
} 
Epstein, B. (2014). Social objects without intentions. In A. Konzelmann-Ziv \& H. B. Schmid (Eds.), Institutions, emotions, and group agents-Contributions to social ontology (pp. 53-68). Dordrecht: Springer.

Epstein, B. (2015). The ant trap: Rebuilding the foundations of the social sciences. Oxford: Oxford University Press.

Geach, P. (1969). God and the soul. London: Routledge.

Griffith, A. M. (2014). Truthmaking and grounding. Inquiry, 57(2), 196-215.

Hansson Wahlberg, T. (2009). Objects in time-Studies of persistence in B-time. Lund: Media-Tryck.

Hansson Wahlberg, T. (2014a). Institutional objects, reductionism and theories of persistence. dialectica, $68(4), 525-562$.

Hansson Wahlberg, T. (2014b). Elder-Vass on the causal power of social structures. Philosophy of the Social Sciences, 44(6), 774-791.

Hansson Wahlberg, T. (2014c). Causally redundant social objects: Rejoinder to Elder-Vass. Philosophy of the Social Sciences, 44(6), 798-809.

Hansson Wahlberg, T. (2017). Meso-level objects, powers, and simultaneous causation. Metaphysica, 18(1), 107-125.

Hansson Wahlberg, T. (forthcoming). Causal powers and social ontology. Synthese. https://doi. org/10.1007/s11229-018-1763-2.

Heil, J. (2012). The universe as we find it. Oxford: Oxford University Press.

Heil, J. (forthcoming). Truthmaking and fundamentality. Synthese. https://doi.org/10.1007/s1122 9-016-1292-9.

Hindriks, F. (2009). Constitutive rules, language, and ontology. Erkenntnis, 71(2), 253-275.

Hindriks, F. (2013). The location problem in social ontology. Synthese, 190(3), 413-437.

Hindriks, F. (2017). Group freedom: A social mechanism account. Philosophy of the Social Science, 47(6), 410-439.

Hindriks, F. ms, The time of a graduation.

Johansson, I. (2003). Searle's monadological construction of social reality. American Journal of Economics and Sociology, 62(1), 233-255.

Kim, J. (1974). Noncausal connections. Noûs, 8(1), 41-52.

Lawson, T. (2013). Emergence and social causation. In R. Groff \& G. Greco (Eds.), Powers and capacities in philosophy: The new aristotelianism (pp. 285-307). New York: Routledge.

Lawson, T. (2016). Comparing conceptions of social ontology: Emergent social entities and/or institutional facts? Journal for the Theory of Social Behaviour, 64(4), 359-399.

Lewis, D. (1973). Causation. Journal of Philosophy, 67(16), 556-567.

Lewis, D. (1986a). On the plurality of worlds. Oxford: Blackwell Publishing.

Lewis, D. (1986b). Events. In Philosophical papers (vol. II, pp. 241-269). Oxford: Oxford University Press.

Lewis, D. (2000/2004). Causation as influence. In J. Collins, et al. (Eds.), Causation and counterfactuals (pp. 75-106). Cambridge: The MIT Press.

Little, D. (2016). New directions in the philosophy of social science. London: Rowman \& Littlefield.

McTaggart, J. E. (1927). The nature of existence (Vol. II). Cambridge: Cambridge University Press.

Mellor, D. H. (1995). The facts of causation. London: Routledge.

Mellor, D. H. (1998). Real time II. London: Routledge.

Mellor, D. H. (2012). Truthmakers for what? In Mind, meaning, and reality: Essays in philosophy (pp. 96-112). Oxford: Oxford University Press.

Mumford, S., \& Anjum, R. L. (2011). Getting causes from powers. Oxford: Oxford University Press.

Prior, A. N. (1996/1998). Some free thinking about time. In P. van Inwagen \& D. W. Zimmerman (Eds.), Metaphysics: The big questions (pp. 104-107). Oxford: Blackwell Publishing.

Putnam, H. (1967). Time and physical geometry. Journal of Philosophy, 64(8), 240-247.

Reichenbach, H. (1958). The philosophy of space and time. New York: Dover Publications.

Russell, B. (1903). The principles of mathematics. Cambridge: Cambridge University Press.

Salmon, W. C. (1984). Scientific explanation and the causal structure of the world. Princeton: Princeton University Press.

Schaffer, J. (2009). On what grounds what. In D. J. Chalmers, et al. (Eds.), Metametaphysics: New essays on the foundations of ontology (pp. 347-383). Oxford: Oxford University Press.

Schaffer, J. (2010). The least discerning and most promiscuous truthmaker. Philosophical Quarterly, 60(239), 307-324. 
Schaffer, J. (forthcoming). Anchoring as grounding: On Epstein's the ant trap. Philosophy and Phenomenological Research. Draft of 20 April 2017 downloaded from www.jonathanschaffer.org, September 2018 .

Searle, J. R. (1969). Speech acts-An essay in the philosophy of language. Cambridge: Cambridge University Press.

Searle, J. R. (1975/1979). A taxonomy of illocutionary acts. In Expression and meaning-Studies in the theory of speech acts (pp. 1-29). Cambridge: Cambridge University Press.

Searle, J. R. (1983). Intentionality. Cambridge: Cambridge University Press.

Searle, J. R. (1989). How performatives work. Linguistics and Philosophy, 12(5), 535-558.

Searle, J. R. (1995). The construction of social reality. London: Penguin Books.

Searle, J. R. (2001). Rationality in action. Cambridge: The MIT Press.

Searle, J. R. (2003). Reply to Barry Smith. American Journal of Economics and Sociology, 62(1), 299-309.

Searle, J. R. (2006). Social ontology: Some basic principles. Anthropological Theory, 1, 12-29.

Searle, J. R. (2010). Making the social world: The structure of human civilization. Oxford: Oxford University Press.

Searle, J. R. (2014). Are there social objects? In M. Galloti \& J. Michael (Eds.), Perspectives on social ontology and social cognition (pp. 17-26). Dordrecht: Springer.

Shoemaker, S. (1980/1997). Causality and properties. In D. H. Mellor \& A. Oliver (Eds.), Properties (pp. 228-254). Oxford: Oxford University Press.

Sider, T. (2001). Four-dimensionalism: An ontology of persistence and time. Oxford: Oxford University Press.

Sider, T. (2011). Writing the book of the world. Oxford: Oxford University Press.

Sklar, L. (1974). Space, time, and spacetime. Berkeley: University of California Press.

Smit, J. P., \& Buekens, F. (2017). How to do things without words: A theory of declarations. Philosophy of the Social Sciences, 47(3), 235-254.

Smith, B. (2014). Document acts. In A. Konzelmann-Ziv \& H. B. Schmid (Eds.), Institutions, emotions, and group agents-Contributions to social ontology (pp. 19-23). Dordrecht: Springer.

Tahko, T. E. (2013). Truth-grounding and transitivity. Thought, 2(4), 332-340.

Taylor, E. F., \& Wheeler, J. A. (1992). Spacetime physics: Introduction to special relativity (2nd ed.). New York: W. H. Freeman and Company.

Thomasson, A. (2003). Foundations for a social ontology. Proto-Sociology: An International Journal of Interdisciplinary Research, 18-19, 269-290.

Tooley, M. (1997). Time, tense and causation. Oxford: Oxford University Press.

Woodward, J. (2003). Making things happen. Oxford: Oxford University Press.

Zimmerman, D. (2002). The constitution of persons by bodies: A critique of Lynne Rudder Baker's theory of material constitution. Philosophical Topics, 30(1), 295-338.

Publisher's Note Springer Nature remains neutral with regard to jurisdictional claims in published maps and institutional affiliations. 